\title{
HUBUNGAN USIA, PENDIDIKAN DAN PARITAS DENGAN PENGGUNAAN AKDR DI PUSKESMAS DOLODUO KABUPATEN BOLAANG MONGONDOW
}

\author{
${ }^{1}$ Wiwin Windasari Ibrahim, ${ }^{2}$ Yuliana Misar, ${ }^{3}$ Fatmah Zakaria \\ 123)Program Studi D-IV Bidan Pendidik Fakultas IImu Kesehatan Universitas Muhammadiyah \\ Gorontalo, Gorontalo 2017, Indonesia \\ e-mail : wiwinibrahim03@yahoo.com
}

\begin{abstract}
The family planning program (KB) in Indonesia has been recognized nationally and internationally as one of the programs that has significantly reduced fertility rates. The purpose of this study was to determine the relationship between age, education and parity with the use of IUD. This research was conducted at Puskesmas Doloduo Bolaang Mongondow District on August 8 until September 30th. This research is an analytic correlation research using cross sectional approach. The population in this study are all active acceptors of 850 people in the area of Puskesmas Doloduo Bolaang Mongondow Utara. Sample in research that researched 85 respondent, with technique of accidental sampling sampling. Based on the Research Methods show that there is a relationship of age, education, and parity with the use of akdr in Puskesmas Doloduo Bolaang Mongondow District. Because $p$ value $0,025 \quad(<0,05)$.
\end{abstract}

Keywords: Age, Parity, Education, IUD

\section{Abstrak}

Program keluarga berencana (KB) di Indonesia telah diakui secara nasional dan internasional sebagai salah satu program yang telah berhasil menurunkan angka fertilitas secara nyata. Tujuan penelitian ini untuk mengetahui hubungan usia, pendidikan dan paritas dengan penggunaan AKDR. Penelitian ini dilakukan di Puskesmas Doloduo Kabupaten Bolaang Mongondow pada tanggal 08 Agustus sampai 30 September. Penelitian ini merupakan penelitian korelasi analitik dengan menggunakan pendekatan cross sectional. Populasi dalam penelitian ini adalah semua akseptor aktif sejumlah 850 orang di wilayah Puskesmas Doloduo Kabupaten Bolaang Mongondow. Sampel dalam penelitian yaitu diteliti 85 responden, dengan tekhnik pengambilan sample accidental sampling. Berdasarkan Metode Penelitian menunjukan bahwa ada hubungan usia, pendidikan, dan paritas dengan penggunaan akdr di Puskesmas Doloduo Kabupaten Bolaang Mongondow. Karena p value 0,025 $(<0,05)$.

Kata Kunci : Usia, Paritas, Pendidikan, IUD 


\section{PENDAHULUAN}

Menurut data organisasi kesehatan dunia (WHO), kematian ibu diperkirakan sebanyak 500.000 kematian setiap tahun, 99\% diantaranya terjadi di negara berkembang. Menurut Millenium Development Goals, dari lima juta kelahiran yang terjadi di Indonesia setiap tahun, diperkirakan 20.000 ibu meninggal akibat komplikasi kehamilan dan persalinan.

Salah satu strategi pelaksanaan program KB seperti tercantum dalam Rencana Pembangunan Jangka Menengah (RPJM) tahun 2010 sampai 2014 ialah meningkatnya penggunaan metode kontrasepsi jangka panjang (MKJP) seperti Intra Uterine Device (IUD) atau alat kontrasepsi dalam rahim (AKDR). AKDR merupakan salah satu jenis alat kontrasepsi jangka panjang yang ideal dalam upaya menjarangkan kehamilan.

Indonesia mengalami peningkatan laju pertumbuhan penduduk dari $1,45 \%$ (1900 sampai 2000) menjadi 1,49\% (2000 sampai 2010), (Sardjuani, 2012). Berdasarkan sensus penduduk (SP) 2010, dalam periode 10 tahun (2000 sampai 2010) jumlah penduduk Indonesia meningkat sebanyak 32,5 juta jiwa, yaitu dari sebanyak 205,8 juta jiwa menjadi sebanyak 237,6 juta jiwa (BPS SP, 2010). Hal ini menunjukkan bahwa kuantitas penduduk Indonesia merupakan permasalahan strategis.

AKDR merupakan kontrasepsi yang dimasukkan melalui serviks dan dipasang didalam uterus. AKDR mencegah kehamilan dengan dengan merusak kemampuan hidup sperma dan ovum karena adanya perubahan pada tuba dan cairan uterus. Efektifitas AKDR dalam mencegah kehamilan mencapai $98 \%$ sampai $100 \%$.

Diketahui dari 2982 peserta KB baru di Kabupaten Bolaang Mongondow hingga Desember 2016, jumlah akseptor AKDR yaitu 236 akseptor, pil 827 akseptor, suntikan 1938 akseptor, Implant 481 sedangkan akseptor di wilayah Puskesmas Doloduo yang menggunakan akseptor AKDR yaitu 72 akseptor, pil 432 akseptor, dan suntikan 235 akseptor (Profil BKKBN Bolaang Mongondow, 2016).

Masalah kependudukan dewasa ini merupakan masalah penting yang mendapat perhatian dan pembahasan yang serius dari ahli kependudukan baik di Indonesia maupun diseluruh dunia. Indonesia merupakan salah satu negara dengan jumlah penduduk ke-empat terbesar di dunia setelah Cina, India, dan Amerika Serikat. Indonesia menyumbang sekitar 6 persen penduduk di Asia.

Program keluarga berencana (KB) di Indonesia telah diakui secara nasional dan internasional sebagai salah satu program yang telah berhasil menurunkan angka fertilitas secara nyata. Hal ini dapat dilihat dari TFR Indonesia hasil survey SDKI 2007 sebesar 2,7\% dan menurun menjadi 2,3\% pada SDKI 2012. Namun, program keluarga berencana di Indonesia ini masih tetap menghadapi beberapa masalah penting dalam upaya mempertahankan momentum program yang selama ini telah berhasil dilaksanakan (Sudarianto, 2012).

Di Indonesia jumlah peserta KB AKDR pada tahun 2010 hanya 0,043\%. Metode kontrasepsi AKDR belum dapat menarik minat pasangan usia subur untuk menggunakannya sebagai alat untuk menjarangkan kehamilan. Padahal metode kontrasepsi AKDR ini merupakan salah satu metode 
kontrasepsi jangka panjang (MKJP), yang mempunyai efektifitas 0,6 sampai 0,8 kehamilan dari 100 perempuan dalam satu tahun pertama penggunaan (Saroha, 2009).

Dilihat dari jumlah akseptor masingmasing alat kontrasepsi, diketahui jumlah pengguna AKDR sangat sedikit di banding alat kontrasepsi lain yang lazim digunakan. Namun dalam kenyataannya tingkat keakuratan AKDR lebih tinggi, karena bisa digunakan dalam waktu yang cukup lama dengan efek samping yang minimal (Suratun dkk, 2011).

Berbagai upaya pemerintah telah dilakukan untuk peningkatan penggunaan AKDR diantaranya adalah dengan adanya kebijakan pemasangan AKDR secara gratis kepada pasangan usia subur, penyediaan alat kontrasepsi, tersedianya dukungan anggaran untuk AKDR serta tersedianya dana pelatihan medis tekhnis bagi provider (BKKBN, 2013).

Menurut Henri (2011), menunjukkan bahwa pemakaian kontrasepsi AKDR di Indonesia masih relatif rendah. Hanya $18 \%$ dari pemakai kontrasepsi memilih AKDR sebagai cara untuk mengatur kehamilan. Sebagian besar kontrasepsi ini digunakan oleh wanita yang berpendidikan rendah (SLTP kebawah), berumur relatif tua (30 tahun atau lebih), bekerja, memiliki tingkat kesejahteraan tergolong mampu dan memiliki anak yang masih hidup lebih dari 2 dua.

Tingkat paritas mempunyai pengaruh yang signifikan terhadap penggunaan AKDR. Semakin banyak jumlah anak yang dilahirkan semakin tinggi keinginan responden untuk membatasi kelahiran. Pada akhirnya hal ini akan mendorong responden untuk menggunakan AKDR. Usia di atas 20 tahun merupakan masa menjarangkan dan mencegah kehamilan sehingga pilihan kontrasepsi lebih ditujukan pada kontrasepsi jangka panjang. Pendidikan memiliki peranan yang penting dalam menentukan kualitas manusia, dengan pendidikan manusia dianggap akan memperoleh pengetahuan. Semakin tinggi pendidikan, hidup manusia semakin berkualitas.

Prosedur medis, termasuk pemeriksaan pelvik diperlukan dalam pemasangan AKDR seringkali menimbulkan perasaan takut selama pemasangan. Ketakutan juga dapat terjadi akibat pengalaman individual orang lain yang mengalami nyeri dan perdarahan (spotting) terjadi segera setelah pemasangan AKDR. Ketakutan akan keluarnya material AKDR dari rahim atau jalan lahir serta perasaan malas atau risih karena harus memeriksa posisi benang AKDR dari waktu ke waktu. Perasaan risih dan malu karena harus membuka pakaian dalam dan memperlihatkan alat kemaluan pada orang lain (pemeriksa atau bidan atau dokter) serta pandangan bahwa AKDR dapat mempengaruhi kenyamanan dalam hubungan seksual, beberapa hal inilah tanggapan masyarakat sehingga mereka kurang berminat menggunakan AKDR (Erfand, 2011).

Sering terjadi perbedaan pendapat dimasyarakat tentang boleh tidaknya menggunakan AKDR atau mengikuti program $K B$, dimana ada yg mengatakan boleh dan ada yang tidak, padahal dalam Al-qur'an banyak sekali ayat yang memberikan petunjuk yang perlu kita laksanakan dalam kaitannya dengan KB, antara lain dalam surat An-Nisa' ayat 9 yang artinya "dan hendaklah takut pada Allah orang-orang yang seandainya meninggalkan dibelakang mereka anak- 
anak yang lemah. Mereka khawatir terhadap kesejahteraan mereka. Oleh sebab itu hendaklah mereka bertaqwa kepada Allah dan hendaklah mereka mengucapkan perkataan yang benar".

Dari hasil survei pada tanggal 5 Juli 2017, di Puskesmas Doloduo pada 12 akseptor KB yang berkunjung dengan menunjukkan 8 ibu yang menggunakan AKDR yang berusia diatas 33 tahun sedangkan yang 4 berusia antara 20 sampai 25 tahun, sementara yang mempunyai anak lebih dari 3 ada 9 orang dan 3 lainnya memiliki anak kurang dari 3. Berdasarkan pernyataan sebelumnya, yaitu angka kelahiran yang masih tinggi dan dengan tingkat keefektifan AKDR yang tinggi, namun minat untuk menggunakan AKDR yang rendah perlu di lakukan penelitian untuk mengetahui pengaruh usia dan paritas terhadap penggunaan AKDR.

\section{METODE PENELITIAN}

Jenis penelitian ini adalah Corelasi analytic dengan menggunakan pendekatan cross sectional. Sampel dalam penelitian ini berjumlah 85 akseptor KB aktif. Penelitian ini dilakukan di Wilayah Kerja Puskesmas Doloduo Kabupaten Bolaang Mongondow pada tanggal 08 Agustus sampai 30 September. Tekhnik pengambilan sampel menggunakan Accidental sampling. Tekhnik pengumpulan data dalam penelitian ini menggunakan lembar observasi, wawancara dan dokumentasi.

Tekhnik analisis data dalam penelitian ini menggunakan analisis data Univariat dengan rumus :

$\mathrm{P}=\frac{f}{\sum n} \times 100 \%$
Analisis

data

Bivariat menggunakan Chi Square $\left(x^{2}\right)$. Analisis bivariat dilakukan untuk melihat hubungan variabel bebas terhadap variabel terikat.

\section{HASIL DAN PEMBAHASAN \\ Karakteristik Responden}

Berdasarkan Tabel 1 diketahui bahwa responden berusia 20 sampai 35 tahun lebih banyak dengan jumlah 52 orang $(61,2 \%)$ dibandingkan dengan usia $>36$ tahun berjumlah 16 (18,8\%).

Berdasarkan Tabel 2 diketahui bahwa responden dengan pendidikan rendah merupakan responden terbanyak berjumlah $46 \quad(54,1 \%)$ dibandingkan dengan Pendidikan Tinggi yakni 39 (45,9\%).

Tabel 1. Distribusi

Karekteristik Responden Berdasarkan Usia

\begin{tabular}{ccc}
\hline $\begin{array}{c}\text { Usia } \\
\text { (tahun) }\end{array}$ & $\begin{array}{c}\text { Frekuensi } \\
\text { (f) }\end{array}$ & $\begin{array}{c}\text { Persentase } \\
(\%)\end{array}$ \\
\hline$<19$ & 17 & 20 \\
$20-35$ & 52 & 61,2 \\
$>36$ & 16 & 18,8 \\
\hline Jumlah & 85 & 100 \\
\hline
\end{tabular}

Sumber : Data primer, 2017

Tabel 2. Distribusi

Karekteristik Responden Berdasarkan Pendidikan

\begin{tabular}{ccc}
\hline Pendidikan & $\begin{array}{c}\text { Frekuensi } \\
(\mathrm{f})\end{array}$ & $\begin{array}{c}\text { Persentase } \\
(\%)\end{array}$ \\
\hline $\begin{array}{c}\text { Pendidikan } \\
\text { Dasar }\end{array}$ & 46 & 54,1 \\
$\begin{array}{c}\text { Pendidikan } \\
\text { Tinggi }\end{array}$ & 39 & 45,9 \\
\hline Jumlah & 85 & 100 \\
\hline Sumber : Data primer, 2017
\end{tabular}

Sumber : Data primer, 2017 
Tabel 3. Distribusi Karekteristik Responden Berdasarkan Paritas

\begin{tabular}{ccc}
\hline Paritas & $\begin{array}{c}\text { Frekuensi } \\
\text { (f) }\end{array}$ & $\begin{array}{c}\text { Persentase } \\
(\%)\end{array}$ \\
\hline 1 & 20 & 23,5 \\
$2-3$ & 56 & 65,9 \\
$>4$ & 9 & 10,6 \\
\hline Jumlah & 85 & 100
\end{tabular}

Sumber : Data primer, 2017

Berdasarkan Tabel 3 diatas responden dengan paritas 2 sampai 3 merupakan responden terbanyak pada penelitian ini berjumlah $56 \quad(65,9 \%)$ dibandingkan dengan paritas $\geq 4(10,6 \%)$.

Tabel 4. Distribusi

Karekteristik Responden Pengguna AKDR

\begin{tabular}{ccc}
\hline $\begin{array}{c}\text { Penggunaan } \\
\text { AKDR }\end{array}$ & $\begin{array}{c}\text { Frekuensi } \\
\text { (f) }\end{array}$ & $\begin{array}{c}\text { Persentase } \\
(\%)\end{array}$ \\
\hline Menggunakan & 18 & 21,2 \\
Tidak & 67 & 78,8 \\
Menggunakan & & \\
\hline Jumlah & 85 & 100 \\
\hline
\end{tabular}

Sumber : Data primer, 2017

Berdasarkan Tabel 4 diatas yang tidak menggunakan AKDR lebih banyak berjumlah 67 responden (78,8\%) dibandingkan dengan yang menggunakan AKDR yakni 18 responden $(21,2 \%)$

\section{Analisis Bivariat Responden}

Hasil penelitian yang disajikan pada Tabel 5 menunjukkan bahwa akseptor dengan usia <19 tahun yang menggunakan AKDR terdapat 1 akseptor (5,9\%) dibandingkan dengan usia 20 sampai 35 yakni 10 (19,2\%). Hasil uji statistik dengan menggunakan chi square antara usia < 19 sampai dengan $>36$ dengan penggunaan kontrasepsi AKDR tabel diperoleh nilai $p$ value 0,025 $(p<0,05)$.

Berdasarkan Tabel 6, akseptor dengan pendidikan dasar menggunakan
AKDR berjumlah 4 (8,7\%) dibandingkan dengan pendidkan tinggi yakni 14 (35,9\%). Hasil uji statistik dengan menggunakan chi square pada variabel pendidikan dengan penggunaan kontrasepsi AKDR diperoleh nilai $p$ value $0,002(p<0,05)$.

Berdasarkan Tabel 7, akseptor dengan paritas 1 menggunakan AKDR berjumlah $0(0 \%)$ dibandingkan dengan paritas $>4$ yakni 5 (55,6\%). Hasil uji statistik dengan menggunakan chi square pada variabel paritas dengan penggunaan kontrasepsi AKDR diperoleh nilai $p$ value $0,003(p<0,05)$.

Berdasarkan hasil penelitian bahwa usia <19 tahun yang menggunakan AKDR terdapat 1 akseptor (5,9\%) dibandingkan dengan usia 20-35 yakni 10 (19,2\%). Hasil uji statistik dengan menggunakan chi square antara usia <19 sampai dengan >36 dengan penggunaan kontrasepsi AKDR diperoleh nilai $p$ value $0,025(p<0,05)$. Kesimpulannya ha diterima, bahwa terdapat hubungan yang signifikan antara usia akseptor dengan penggunaan AKDR.

Ibu dengan usia muda cenderung memiliki ketakutan dan malu terhadap hal-hal yang menurut mereka tabu. Sehingga enggan untuk menggunakan kontrasepsi dalam rahim. Ketidak tahuan akan keuntungan menggunakan AKDR bagi ibu usia muda dikarenakan pengetahuan tentang alat kontrasepsi dalam rahim yang masih rendah. Banyaknya isu tentang kejadian komplikasi yang ditimbulkan membuat ketakutan dari pasangan untuk menggunakan terutama bagi ibu dengan usia muda. Pada ibu dengan usia muda cenderung merasa malu jika harus menggunakan AKDR, karena merasa 
Tabel 5. Hubungan Usia Dengan Penggunaan Alat Kontrasepsi Dalam Rahim

\begin{tabular}{|c|c|c|c|c|c|c|c|c|}
\hline \multirow{3}{*}{ No } & \multirow{3}{*}{ Usia } & \multicolumn{4}{|c|}{ Penggunaan AKDR } & & & \multirow{3}{*}{$X^{2}$ hitung } \\
\hline & & \multicolumn{2}{|c|}{ Menggunakan } & \multicolumn{2}{|c|}{$\begin{array}{c}\text { Tidak } \\
\text { menggunakan }\end{array}$} & \multicolumn{2}{|c|}{ Jumlah } & \\
\hline & & $\mathrm{n}$ & $\%$ & $\mathrm{~N}$ & $\%$ & $n$ & $\%$ & \\
\hline 1 & $<19$ & 1 & 5,9 & 16 & 94,1 & 17 & 100 & \\
\hline 2 & $20-35$ & 10 & 19,2 & 42 & 80,8 & 52 & 100 & 0,025 \\
\hline \multirow[t]{2}{*}{3} & $>36$ & 7 & 43,8 & 9 & 56,2 & 16 & 100 & \\
\hline & Total & 18 & 21,2 & 67 & 78,8 & 85 & 100 & \\
\hline
\end{tabular}

Sumber: Data primer, 2017

Tabel 6. Hubungan Tingkat Pendidikan Dengan Penggunaan Alat Kontrasepsi

Dalam Rahim

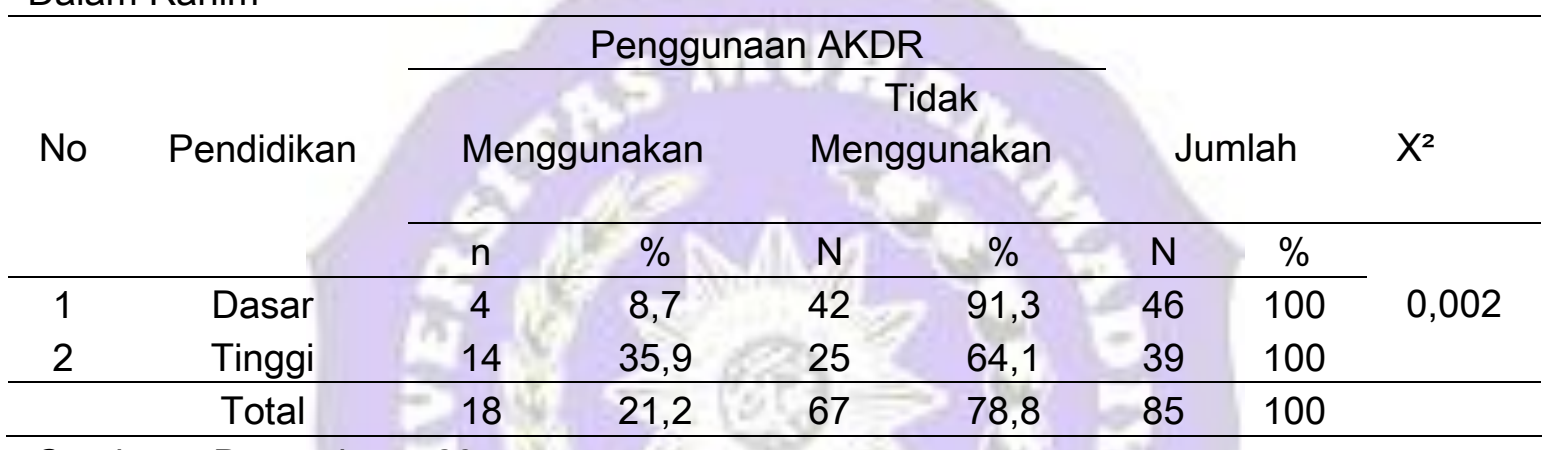

Sumber: Data primer, 2017

Tabel 7. Hubungan Paritas Dengan Penggunaan Alat Kontrasepsi Dalam Rahim

\begin{tabular}{|c|c|c|c|c|c|c|c|c|}
\hline \multirow{3}{*}{$\begin{array}{l}N \\
0\end{array}$} & \multirow{3}{*}{ Paritas } & \multicolumn{4}{|c|}{ Penggunaan AKDR } & \multirow[t]{2}{*}{$\mathrm{As}$} & & \multirow{3}{*}{$X^{2}$} \\
\hline & & \multicolumn{2}{|c|}{ Menggunakan } & mer & lakan & & & \\
\hline & & $\mathrm{N}$ & $\%$ & $\mathrm{~N}$ & $\%$ & & $\%$ & \\
\hline 1 & 1 & & & 20 & 100 & 20 & 100 & \\
\hline 2 & $2-3$ & 13 & 23,2 & 43 & 76,8 & 56 & 100 & 0,003 \\
\hline 3 & $>4$ & 5 & 55,6 & 4 & 44,4 & 9 & 100 & \\
\hline & Jumlah & 18 & 21,2 & 67 & 78,8 & 85 & 100 & \\
\hline
\end{tabular}

Sumber: Data primer, 2017

Menurut asumsi peneliti dengan melihat hasil pengelolahan data tersebut menunjukkan bahwa responden dengan usia <19 tahun sedikit yang menggunakan metode kontrasepsi akdr, karena suami tidak mengizinkan istri menggunakan kontrasepsi hanya sedikit istri yang berani memakai metode kontrasepsi tersebut dukungan dari suami dalam penggunaan kontrasepsi sangat diperlukan karena tanpa adanya 
dukungan dari suami rasa nyaman untuk menggunakan kontrasepsi tidak akan didapatkan, dalam memilih metode kontrasepsi pasangan suami isteri membicarakan atau mempertimbangkan secara bersama sama untuk memilih metode kontrasepsi terbaik yang disetujui bersama, saling bekerja sama dalam penggunaan kontrasepsi, memperhatikan tanda-tanda bahaya penggunaan kontrasepsi dan menanggung biaya untuk penggunaan kontrasepsi. Berdasarkan hasil wawancara peneliti dengan responden pada saat penelitian, hal tersebut disebabkan karena responden tidak mengetahu karena kebanyakan responden tidak cocok dan takut dalam menggunakan kontrasepsi tersebut sehingga terjadi efek samping pada akseptor tersebut.

Penelitian serupa yang dilakukan oleh Imbarwati, 2019 "Beberapa faktor yang berkaitan dengan penggunaan KB IUD pada peserta KB non IUD di Kecamatan Pedurungan Kota Semarang" dimana hasil penelitian menunjukan bahwa penggunaan IUD terbanyak pada usia dewasa (20 sampai 35 tahun) sebanyak 76,4\% sementara pada usia muda sangat rendah yakni 23,6\%.

Menurut Notoatmodjo (2003) umur adalah salah satu faktor yang mempengaruhi prilaku seseorang dalam pemakaian alat kontrasepsi. Mereka yang berumur terlalu muda dan terlalu tua mempunyai peluang lebih kecil untuk menggunakan alat kontrasepsi. Pola dasar penggunaan alat kontrasepsi yang rasional pada umur 20 sampai 30 tahun alat kontrasepsi yang mempunyai refersibilitas yang tinggi karena pada umur tersebut PUS masih berkeinginan untuk mempunyai anak.

Dari hasil ini dapat di peroleh kesimpulan bahwa usia muda mempunyai pengaruh yang signifikan dalam menentukan penggunaan AKDR.

\section{Hubungan Tingkat Pendidikan dengan Penggunaan AKDR}

Berdasarkan penelitian bahwa akseptor dengan pendidikan dasar menggunakan AKDR berjumlah 4 $(8,7 \%)$ dibandingkan dengan pendidkan tinggi yakni 14 (35,9\%). Hasil uji statistik dengan menggunakan chi square pada variabel pendidikan dengan penggunaan kontrasepsi AKDR diperoleh nilai $p$ value $0,002(p<0,05)$. Kesimpulannya bahwa terdapat hubungan yang signifikan antara pendidikan akseptor dengan penggunaan AKDR.

Menurut asumsi peneliti dengan melihat hasil pengelolahan data tersebut menunjukkan bahwa responden dengan tingkat pendidikan sedikit yang menggunakan metode kontrasepsi akdr dengan pendidikan dasar, karena kurangnya pengetahuan menggunakan kontrasepsi akdr. Sedikit yang berani memakai metode kontrasepsi tersebut karena adanya rasa takut dan malu. Berdasarkan hasil wawancara peneliti dengan responden pada saat penelitian, hal tersebut disebabkan karena responden tidak mengetahi karena kebanyakan responden tidak tau dan takut dalam menggunakan kontrasepsi tersebut sehingga terjadi efek samping.

Tingkat pendidikan akseptor merupakan hal yang turut berperan terhadap pemilihan alat kontrasepsi yang ingin dipakai. Setiap informasi yang disampaikan peroleh diolah sehingga dapat diterima oleh nalar. Hal ini dapat 
dilihat dari penggunaan AKDR, bahwa tingkat pendidikan rendah lebih sedikit menggunakan AKDR dibanding yang berpendidikan tinggi.

Pengetahuan pasangan usia subur akan berbagai macam alat kontrasepsi yang disediakan ikut berperan terhadap penggunaan alat kontrasepsi. Kurangnya informasi yang didapat juga turut berpengaruh terhadap keadaan ini. Informasi yang didapat dari sumber yang salahpun akan memberikan efek negatif bagi calon akseptor sehingga menimbulkan ketakutan untuk menggunakan AKDR.

Informasi yang didapat saat penelitian dari akseptor seperti nyeri pada saat haid dan keluarnya darah yang banyak ketika haid merupakan faktor yang tuurut berperan terhadap penggunaan AKDR. Hal ini membutuhkan penyuluhan dan konseling untuk membuka dan menambah pengetahuan ibu tentang hal-hal menyangkut AKDR.

Hal ini sejalan dengan penelitian yang dilakukan oleh Iga Sukma Anggriani, 2015 "Hubungan karakteristik ibu dengan penggunaan alat kontrasepsi IUD di puskesmas Mergansan Yogyakarta" dimana berdasarkan uji statistik dengan menggunakan uji chi square di peroleh hasil bahwa nilai $p$ value $0,018 \quad(p<0,05) \quad$ menunjukkan bahwa pendidikan signifikan terhadap penggunaan AKDR.

\section{Hubungan Paritas dengan Penggunaan AKDR}

Berdasarkan penelitian bahwa akseptor dengan primipara menggunakan AKDR berjumlah $0(0 \%)$ dibandingkan dengan grande multi para yakni $5(55,6 \%)$. Hasil uji statistik dengan menggunakan chi square pada variabel paritas dengan penggunaan kontrasepsi AKDR diperoleh nilai $p$ value 0,003 ( $p$ $<0,05)$. Kesimpulannya bahwa terdapat hubungan yang signifikan antara paritas dengan penggunaan AKDR.

Menurut asumsi peneliti dengan melihat hasil pengelolahan data tersebut menunjukkan bahwa dengan penggunaan akdr pada primi tidak ada yang menggunakan karena dalam pemilihan metode kontrasepsi kebanyakan responden memilih metode kontrasepsi efektif dalam memilih metode kontrasepsi suntik karena takut dengan cara pemasangan akdr. Pengetahuan akseptor KB sangat erat kaitannya terhadap pemilihan alat kontrasepsi, karena dengan adanya pengetahuan yang rendah terhadap metode kontrasepsi tertentu akan merubah cara pandang akseptor dalam menentukan kontrasepsi yang paling sesuai dan efektif digunakan sehingga membuat pengguna KB lebih nyaman terhadap kontrasepsi tersebut. Dan dengan multipara lebih banyak yang menggunakan metode kontrasepsi akdr yang paling sesuai bagi pengguna itu sendiri.

Rendahnya minat memakai AKDR pada ibu yang memiliki anak 1 karena ketakutan akan alat yang metodenya harus di masukkan ke dalam rahim. Mereka menganggap itu akan merusak alat reproduksinya. Dukungan suamipun rendah, karena merasa tidak nyaman saat berhubungan. Kecemasan akan penggunaan AKDR akan masuk menembus dinding rahim dan kekhawatiran efek samping yang ditimbulkan oleh AKDR.

Ibu dengan paritas 1 biasanya juga menghawatirkan tentang kesuburannya, 
ketakutan jika setelah melepas AKDR lama kembali kesuburannya. Penyakit infeksi dan keputihan yang ditimbulkan setelah pemasangan AKDR merupakan salah satu faktor yang menyebabkan ibu tidak menggunakannya. Sementara pada akseptor yang memiliki anak lebih dari 3 dengan usia di atas 35 tahun menganggap bahwa menggunakan AKDR terlalu lama akan menyulitkan pada saat pencabutan.

Hal ini sejalan dengan penelitian yang dilakukan oleh Fitria Ramadini, 2014 "Hubungan paritas dengan pemilihan metode kontrasepsi jangka panjang di desa Ngares Kecamatan Gedeg Kabupaten Mojokerto" dimana berdasarkan uji statistik dengan menggunakan uji chi square di peroleh hasil bahwa nilai $p$ value $0,015(p<0,05)$ dimana paritas lebih dari 4 tidak berminat menggunakan AKDR. Hal ini menunjukkan bahwa paritas signifikan terhadap penggunaan AKDR.

\section{KESIMPULAN DAN SARAN Kesimpulan}

Dari hasil penelitian mengenai hubungan usia, pendidikan dan paritas dengan penggunaan akdr di puskesmas doloduo kabupaten bolaang mongondow dapat disimpulkan bahwa:

1. Ada hubungan antara usia wanita usia subur dengan penggunaan AKDR

2. Ada hubungan antara pendidikan wanita usia subur dengan penggunaan AKDR

3. Ada hubungan antara paritas wanita usia subur dengan pengguna AKDR

\section{Saran}

1. Untuk Institusi Pendidikan diharapkan hasil peneliti ini dapat memberikan informasi serta digunakan sebagai referensi bagi peneliti selanjutnya dan dapat menjadi bahan penelitian lanjutan tentang penyuluhan dan konseling yang baik sehingga PUS dapat memilih alat kontrasepsi yang tepat untuk digunakan.

2. Untuk Tenaga Kesehatan diharapkan hasil penelitian ini mendorong untuk lebih mengeksistensikan profesi kedepan dengan lebih kosentrasi dalam memperhatikan kualitas tenaga dalam menciptakan SDM yang berkualitas sehingga dapat diandalkan.

3. Untuk tempat penelitian diharapkan agar dapat melakukan penyuluhan dan konseling yang baik sehingga PUS dapat memilih alat kontrasepsi yang tepat untuk digunakan.

4. Bagi Peneliti Selanjutnya diharapkan hasil penelitian ini dapat dijadikan sebagai bahan pembelajaran sehingga dapat diterapkan di tempat kerja kelak dan dalam pelaksanaan bidan pendidik.

\section{DAFTAR PUSTAKA}

BKKBN . 2016. Profil Badan

Kependudukan dan Keluarga

Berencana Nasional Bolaang Mongondow.

Badan Kependudukan dan Keluarga Berencana. 2013. Indonesia

Dinas Kesehatan Bolaang Mongondow. 2016. Laporan KIA-KB, Bidang Binkesmas, Dinas Kesehatan Provinsi Sulawesi Utara.

Badan Pusat Statistik, Sensus Penduduk 2010, http://sp2010.bps.go.id/

Erfand. 2011. Permasalahan Kontrasepsi 
IUD di Puskesmas.

Henri Sutanti. 2013. Hubungan Pengetahuan dan Sikap Dengan Pemilihan Kontrasepsi IUD Pada Wanita Usia Subur di Desa Sepanjang Wilayah Kerja Puskesmas Sepanjang Kabupaten Banyuwangi Tahun 2013.
Saroha. 2009. Kesehatan Reproduksi dan Kontrasepsi. Trans Media Info. Jakarta

KB Pasangan Usia Subur Terhadap Kehamilan Yang Tidak Diinginkan.

Suratun, dkk. 2011. Pelayanan Keluarga Berencana dan Pelayanan Kontrasepsi, Trans Info Media, Jakarta. 